\title{
Non Intrusive U Value Metering
}

\author{
Nikos Sakkas ${ }^{1}$, Jaume Madrid Valls ${ }^{2}$, Costas Daskalakis ${ }^{1}$, Evangelos Kaltsis ${ }^{1}$ \\ ${ }^{1}$ Applied Industrial Technologies Ltd., Gerakas, Greece \\ ${ }^{2}$ Terrassa Hospital, Catalonia, Spain \\ Email: info@apintech.com
}

Received 18 May 2015; accepted 6 June 2015; published 9 June 2015

Copyright (C) 2015 by authors and Scientific Research Publishing Inc.

This work is licensed under the Creative Commons Attribution International License (CC BY).

http://creativecommons.org/licenses/by/4.0/

(c) (i) Open Access

\section{Abstract}

The significance of $U$ values in buildings' shell energy performance is well known in the scientific community as well as in the construction sector. In addition, conducting a validation of the energy performance of a building often requires the knowledge of real $U$ value figures, since their theoretical peers may deviate considerably from the real ones. The theoretical $U$ value of a shell element may be calculated using complex material and surface related information, while its practical validation is conducted usually by equipment that requires tedious installation and constant contact with the examined element. Aim of this paper is to introduce an easily deployed, plug and play, contact less technology, able to provide a reasonable approximation of the building element $U$ value and its variation with external air speed as well as an accurate estimation of the $U$ value change in case of a shell (wall or window) retrofit.

\section{Keywords}

U Value Metering, Retrofit Impact on U Value, Plug and Play and Non-Intrusive Metering, IR Sensing, Wireless Sensor Networks-WSN

\section{Introduction}

Space heating and cooling energy use is growing slowly and remains the most important energy user, responsible for 53\% of household final energy consumption [1]. Therefore, the heat losses and thermal characteristics of the buildings' shell elements, have become an important field for the scientific community and the construction practitioner. Doran et al. [2] suggested that the first step to understand the thermal behavior of a building (wall, roof, etc.) was to investigate the $U$ value of the shell components that frame a building. The $U$ value of a building shell element is the term used in the construction business to describe its thermal performance or, equivalently, the thermal losses the shell element experiences. The lower the $U$ value the better the shell insulation. Thus, $U$ value calculation is of paramount importance for designing and monitoring energy sustainable buildings. 
The issue is further complicated as it is quite common [3] [4] to observe significant deviations between theoretical $U$ values and their actual, metered, values.

$\mathrm{U}$ values may be required in the design phase of a new building, when investigating the performance of various building components (wall, roof, etc.); they may be re-assessed or metered during the building life cycle in order to monitor possible shell elements' wear and how this contributes to the overall building performance. Besides these uses, the importance of the $U$ value can be equally well recognized [5] in energy retrofit schemes, whose purpose typically is to alter (reduce) the actual $U$ values. Hence, the $U$ value change during a refurbishment can provide insight into the actual energy impact as well as safe and important information as to the payback of the related investment.

Realizing the importance of the real $U$ value figures, a number of studies have attempted to identify methods that would measure $U$ values in real conditions. According to Ward [6], the calculation of $U$ values can be done by full contact methods and especially through three dimensional thermal modeling programs. However, these methods usually appear very impractical due to the fact that their deployment requires installing equipment on walls, while cables included in the equipment bring accessibility problems to the surrounding area. Thus, it is easy to understand that $U$ value measurement may be a difficult and intrusive procedure in the case of a functional building. Figure 1 [7] illustrates a full-contact method where five sensing elements are engaged to measure the $U$ value of the wall. One can there appreciate the level of intrusion and potential user inconvenience.

We will present below a practical technological layout that solves many of the problems discussed above. The technology will be based on remote (contact free) monitoring of wall temperatures, which together with the indoor and outdoor temperatures and the air speed can provide for reasonable approximations of the $U$ value. In addition, the technology is particularly promising in the case of $U$ value change assessment, typical to retrofits. As we have emphasized above, the ability to assess a shell retrofit based on actual data is of a paramount importance for the very development of the retrofit industry. Accountability is often poor during retrofits and the technology presented here could contribute towards objective impact information. In fact, the driving force behind this work was the $\mathrm{U}$ value change during retrofits rather than the $\mathrm{U}$ value itself.

\section{Methods}

\subsection{Basic Definitions}

The basic equation for the definition of the $\mathrm{U}$ value is the following:

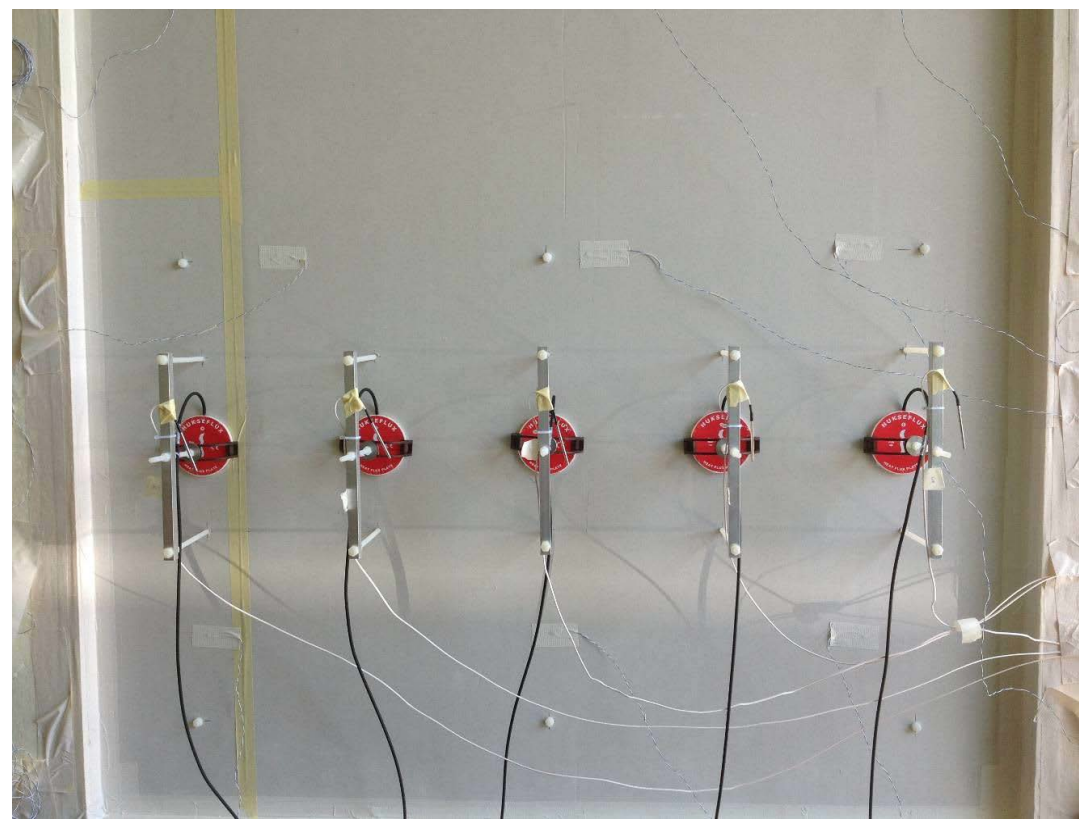

Figure 1. U value measurement by a full-contact method; the five devices shown are heat flux meters. 


$$
\mathrm{Q}=\mathrm{U}\left[\mathrm{T}_{\text {in }}-\mathrm{T}_{\text {out }}\right]
$$

where

$\mathrm{Q}$ are the thermal losses per unit surface and time $\left[\mathrm{W} / \mathrm{m}^{2}\right]$;

$\mathrm{T}_{\text {in }}$ is the inner space temperature $[\mathrm{K}]$;

$\mathrm{T}_{\text {out }}$ is the outer space temperature $[\mathrm{K}]$.

As shown on Figure 1 it is intrusive and tedious to estimate the heat flux, Q, in the above equation. Thus, we will not base our approach directly on this equation.

In addition to the above equation heat flowing through the inner side of a building wall element can be estimated according to the following equation

$$
\mathrm{Q}=\mathrm{h}_{\text {in }}\left[\mathrm{T}_{\text {in }}-\mathrm{T}_{\text {wall, }}\right]
$$

where

$\mathrm{Q}$ are the thermal losses per unit surface and time $\left[\mathrm{W} / \mathrm{m}^{2}\right]$;

$\mathrm{T}_{\text {wall, }}$ is the inner wall temperature $[\mathrm{K}]$;

$\mathrm{h}_{\mathrm{in}}$ is the inner surface resistance $\left[\mathrm{W} / \mathrm{m}^{2} / \mathrm{K}\right]$.

Equating both above equations we end up with the following formula for the $\mathrm{U}$ value calculation

$$
\mathrm{U}=\mathrm{h}_{\text {in }}\left[\mathrm{T}_{\text {in }}-\mathrm{T}_{\text {wall }}\right] /\left[\mathrm{T}_{\text {in }}-\mathrm{T}_{\text {out }}\right] \text {. }
$$

This will be the basic equation that will be used in our investigation. Our calculation method will therefore be based on constant metering of the three temperatures in the above equation.

However, how can we estimate $h_{\text {in }}$ ?

The applicable to our case ISO standard 6946 [8] suggests a set of values that can in most cases be used for $\mathrm{h}_{\mathrm{in}}$. However, it is necessary to stress that the value of $h_{\text {in }}$ may depend a lot on the emissivity of the surface. The values suggested in this standard apply for emissivity $=0.9$ and will not be applicable in cases where the emissivity of the wall element differs significantly from the above typical case.

This is why we claim the method to be a reasonable approximation and not an accurate measurement of the $\mathrm{U}$ value. However, our primary goal is the change of the $U$ value, i.e., the retrofit impact. In this case the uncertainty about $h_{\text {in }}$ becomes irrelevant as, in the usual case, we can safely assume it to be the same before and after the retrofit. In this way it will be factored out from our calculation. Of course, this is only valid in the case of an external retrofit, i.e., when the retrofit activity is carried out on the external wall. If the retrofit activity is carried out on the internal wall then we cannot safely assume that the $h_{\text {in }}$ before and after the retrofit will remain the same. We can however, in this case, use the peer of Equation (1), describing the heat flow through the outer surface. This would be

$$
\mathrm{Q}=\mathrm{h}_{\text {out }}\left[\mathrm{T}_{\text {out }}-\mathrm{T}_{\text {wall,o }}\right]
$$

where

$\mathrm{Q}$ are the thermal losses per unit surface and time $\left[\mathrm{W} / \mathrm{m}^{2}\right]$;

$\mathrm{T}_{\text {wall,o }}$ is the outer wall temperature $[\mathrm{K}]$;

$\mathrm{h}_{\text {out }}$ is the outer surface resistance $[\mathrm{K}]$.

Thus, in the case of internal side retrofitting our metering scheme should focus on the outer surface temperature. Just as in the case of $h_{\text {in }}$, $h_{\text {out }}$ can now be calculated according to the standard. It is important to note that this parameter varies greatly with the air speed, adjacent to the wall, increasing rapidly with it.

An alternative approach [9] uses the expression

$$
\mathrm{Q}=1 / \mathrm{R}_{\text {swall }}\left[\mathrm{T}_{\text {wall, } \mathrm{i}}-\mathrm{T}_{\text {wall, }}\right]
$$

where

$\mathrm{R}_{\text {swall }}$ is the element resistance $\left[\mathrm{m}^{2} \mathrm{~K} / \mathrm{W}\right]$.

By combining Equation (1) and (5) the following expression for the $U$ value can result

$$
\mathrm{U}=1 / \mathrm{R}_{\text {swall }}\left[\mathrm{T}_{\text {wall, } \mathrm{i}}-\mathrm{T}_{\text {wall,o }}\right] /\left[\mathrm{T}_{\text {in }}-\mathrm{T}_{\text {out }}\right] \text {. }
$$

If we were to use Equation (6) we would not need the $h_{\text {in }}$ surface resistance; yet we would need both wall 
temperature values as well as the wall resistance. This, latter value, would depend on the materials composing the investigated wall element and its estimation would, similar to the $h_{i n}$, also introduce some error in the calculation. In the case of a retrofit impact, where $h_{\text {in }}$ is essentially factored out, this method does not present any advantage to out preferred Equation (3). In the case of absolute $U$ value metering it could present some advantage in the case where the estimation of the $\mathrm{R}_{\text {swall }}$ parameter would have some accuracy advantages over that of the surface resistance $h_{\text {in }}$.

\subsection{Wall Temperature}

Our non-contact method for the real time measurement of the $U$ value will be based on three temperatures. The "in" and "out" ambient temperatures present no real difficulty to their accurate measurement.

Thus, one of the challenges of our non-contact approach is to measure the inner wall temperature with a non-contact methodology. This is done via contact-free thermopile technology. A thermopile is essentially an infrared sensor. It produces a signal that depends on all infrared light it receives. Thus, the more far from the wall it is positioned, the more the wall emanating heat (infrared) will be confused with other infrared sources. Although distance is not generally an issue, what is a true issue is the field of view (FOV). Lenses will be required to focus the thermopile on the wall. Figure 2 illustrates the general principle of operation.

The sensor will be restricted, via lenses to an angle of 6 - 8 degrees to avoid interference with other infrared sources. The wall infrared (heat essentially) will thus be the only parameter influencing the sensor and the measured $\Delta \mathrm{T}$ will result to an output value that will allow the direct calculation of the $\mathrm{T}_{\text {obj }}=\mathrm{T}_{\text {wall }}$.

Figure 3 illustrates the installation of the IR sensors used for wall temperature measurement in the case of a wall (side wall mounted) and a window (ceiling mounted) planned for retrofit in a hospital in Terrassa (Catalonia, Spain). Because extensive data collection and testing is planned, a special fixture has been used to place the sensor. Normally we would have simply and conveniently placed the sensor on a desk for a few days. The exact averaging time required for the $U$ value calculation is currently under investigation, although we do not expect it to exceed a few days, especially if we wish to reveal its change with the wind speed.

What if air drafts, due to ventilation, are present in the study space? Such drafts would affect the inner surface resistance and therefore the $U$ value; in fact they would increase it, as convection rapidly increases as wall drift velocity increases.

For this reason we consider as the best option the following: the sensing system will be turned off when ventilation is on. If ventilation is shut off, it would be very unlikely for the wall to experience any drift velocity, from some other source. In such a measurement protocol, the value of the surface resistance coefficient would not be affected by the air movement. As soon as the ventilation is cut off, then the sensing system could be back in work. In practice, measuring $U$ values in construction sites during the construction itself would always be done with no ventilation. Even in working buildings, where ventilation may be used, there will be many hours
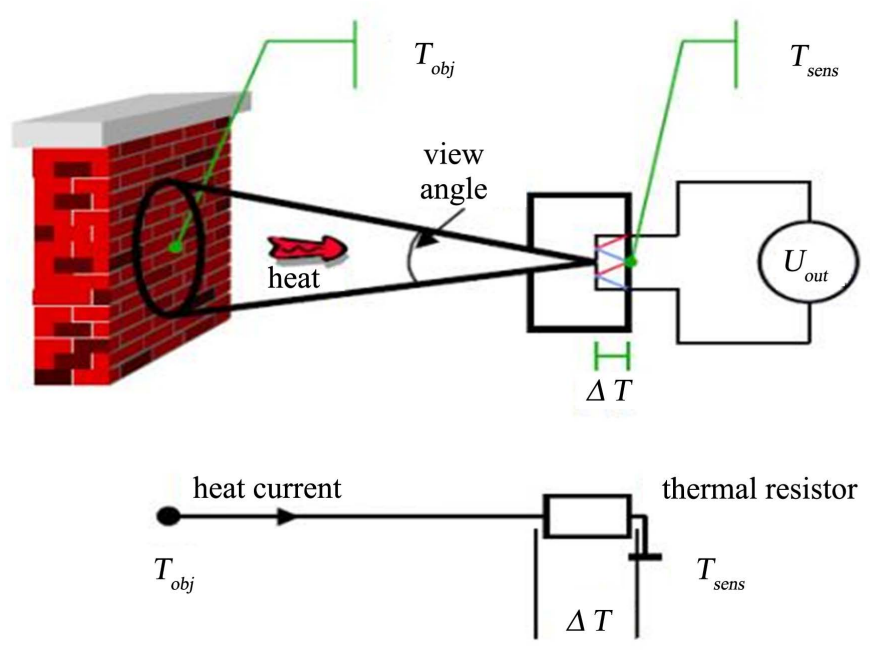

Figure 2. Non-contact, distant measurement of the wall temperature. 

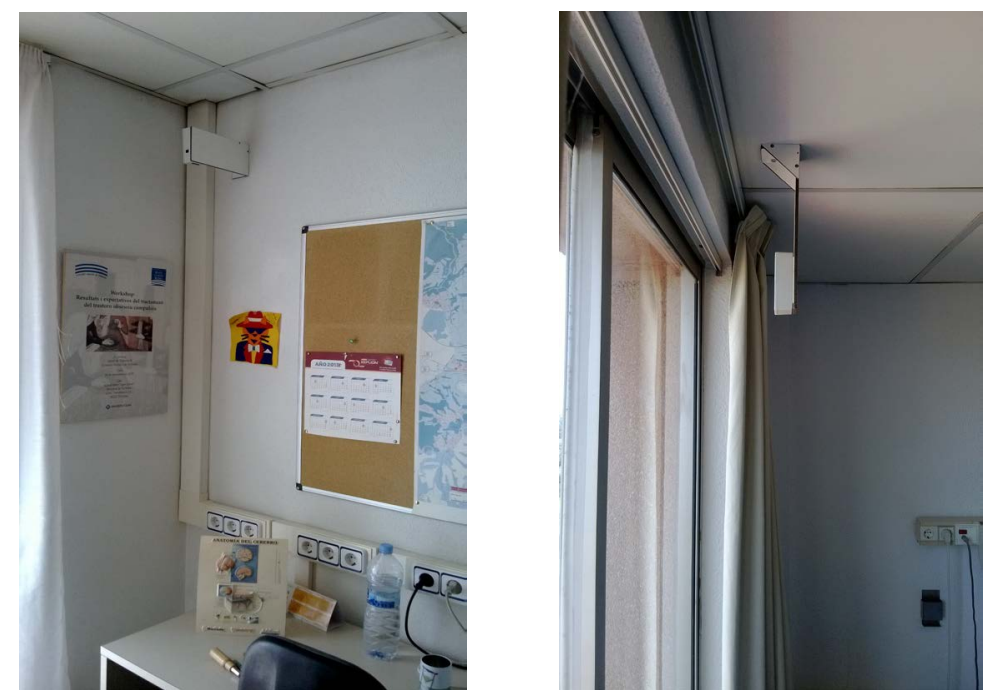

Figure 3. IR wall temperature sensor installation at Terrassa hospital in the case of a wall (side wall mounted) and a window (ceiling mounted) planned for retrofit.

throughout the week (e.g. night) when it will be turned off. Therefore, the impact of changing $\mathrm{h}_{\text {in }}$ values would be effectively eliminated.

There is one more important reason to opt for a night metering protocol. During the day, the sun may affect a lot the surface resistances. In the case of a glazing exposed to sunlight, it may overheat and release its heat to the space, even during winter/early spring time. This would result to negative $U$ values which of course make no sense and are just related to the glazing overheating and the non-steady state conditions. This will be illustrated also in the early data collection scheme that has been carried out in the Terrassa hospital.

Night hours are obviously much less complex thermodynamically and therefore much better for setting up the monitoring scheme.

\subsection{Deployment and Cost}

Contrary to the intrusive and impractical approaches illustrated in Figure 1 the current approach is completely non-intrusive and plug and play. The implementation has been based on the WIRELESS THINGS

(www.wirelessthings.biz) products marketed by our company. Three wireless modules were required, which can under certain circumstances be reduced to just one. These three modules are as follows:

1) An ENVSENSE module scanning the indoor ambient conditions.

2) An ENVSENSE module scanning the outdoor ambient conditions as well as air speed, by connecting our anemometer to the input of the module.

3) An IRSENSE module to scan the appropriate surface temperature, via IR technology.

In a case where the outdoor conditions plus air speed are available by some weather service the second module is no more necessary. Also, the IRSENSE has an embedded capacity to also scan the indoor ambient temperature. However, if this module is placed close to the walls (as in our case illustrated in the above figures) the ambient temperature metered will not be representative of the space temperature; then the first module will also be required. If the placement of the IRSENSE module is not close to a wall then the ambient temperature value it provides will be appropriate and the first module of our configuration will now be redundant.

Thus, the solution requires $1-3$ wireless modules, which are remotely and over the net set up to create a wireless sensor network (wsn), which then reports via a gateway, attached to a USB port of an internet enabled device, to the dashboard application shown in Figure 4. The cost for a full set-up would be up to $1000 \mathrm{E}$ (including the cost of the anemometer), which depending on the possibility to use fewer modules may come down to 400 - $600 \mathrm{E}$. This cost would include the remote setup for one instance and all the data visualization, processing and reporting. The same equipment can of course be used for many, different setups, in which case only an additional cost of $200 \mathrm{E}$, for the remote setup and reporting, would apply. 


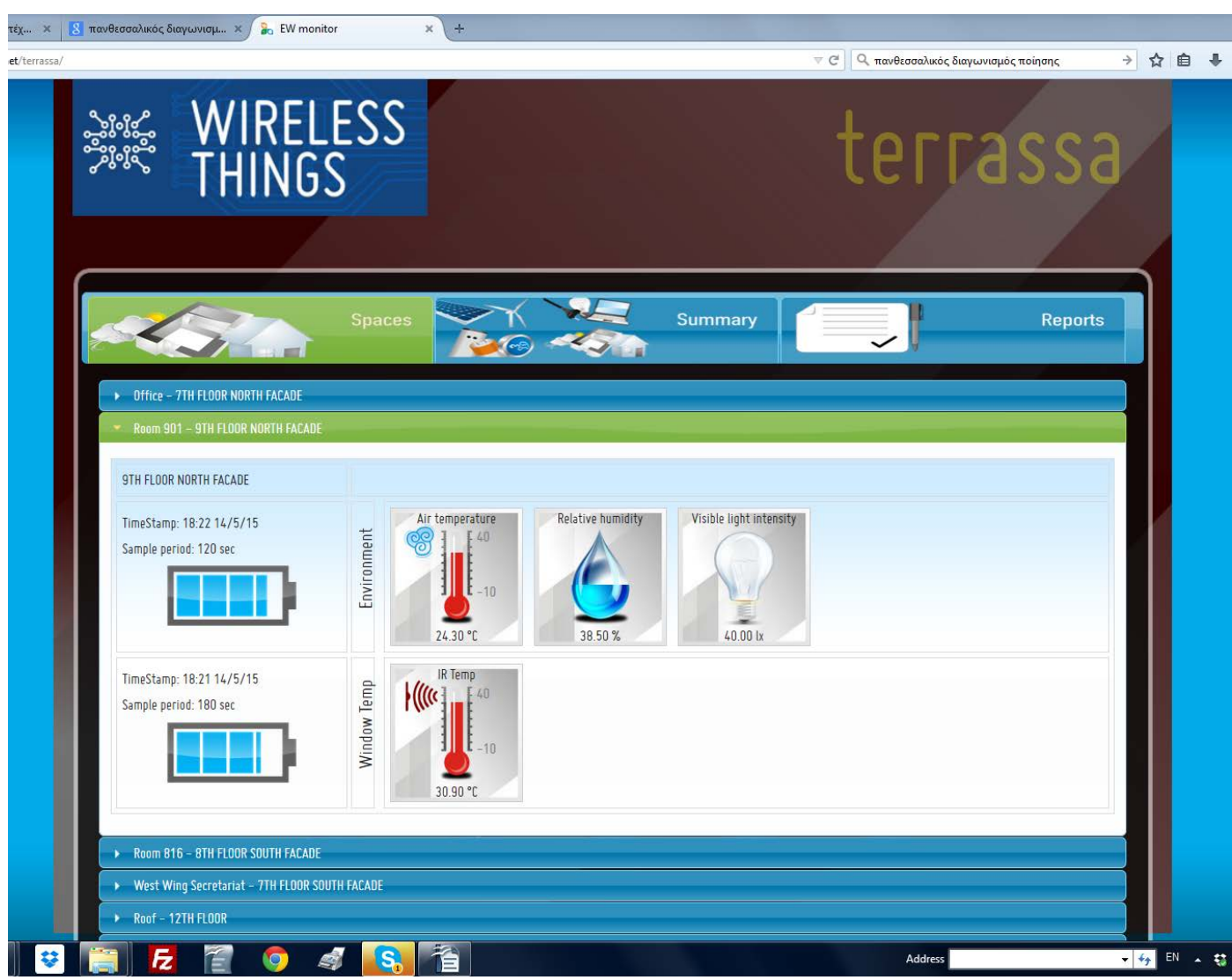

Figure 4. The monitor dashboard for the Terrassa hospital (http://wsn.energywarden.net/terrassa) where the inner ambient temperature as well as inner, IR scanned, wall temperature values are reported. In another screen the outdoor temperatures and the wind speed are shown.

However, one does not need to purchase the equipment. The modules may also be delivered over a leasing scheme (250 E plus shipping cost in two directions). This is a more suitable approach if one does not need a permanent wsn installation or does not plan to use the equipment for metering many building elements.

As to installation limitations, there are some restrictions that must be observed especially with regard to the IR temperature meter. Detailed guidelines are sent to the user so that the measurement does not interfere with neighbor objects. This is potentially the main source of error. One can appreciate from the real Terrassa installation the easiness of deployment, although in this case, because of the long metering campaign, we have used, generally unnecessary, fixtures. In the usual case, the modules can be conveniently placed on some desk, object, etc.

\section{Results}

Four setups have been put in operation at the Terrassa hospital, at areas that are planned for various retrofit activities. The main purpose is not the metering of the actual $U$ value itself but the assessment of its change due to the planned retrofits. For this reason the method and technology presented here seem very appropriate.

The two following graphs illustrate the continuous data collection campaign for the case of a wall (Figure 5) and a window (Figure 6). On these graphs, one can note the three scanned temperatures and the wind speed; the resulting $\mathrm{U} / \mathrm{h}_{\text {in }}$ value is calculated along the lines presented above. We have not introduced the estimation for the $\mathrm{h}_{\mathrm{in}}$ in these graphs. As we have explained above, this should be done as the standard requires. In the case of a retrofit, they will not be required, as they can be safely assumed to be remain the same, under the condition that the wall, whose temperature is metered, is the opposite of the retrofitted one.

One can see the general coherence of the data series; the adverse impact of increased wind on the $U$ value is also demonstrated. In the case of the window (Figure 6), negative, pseudo U values, discussed above, have been 


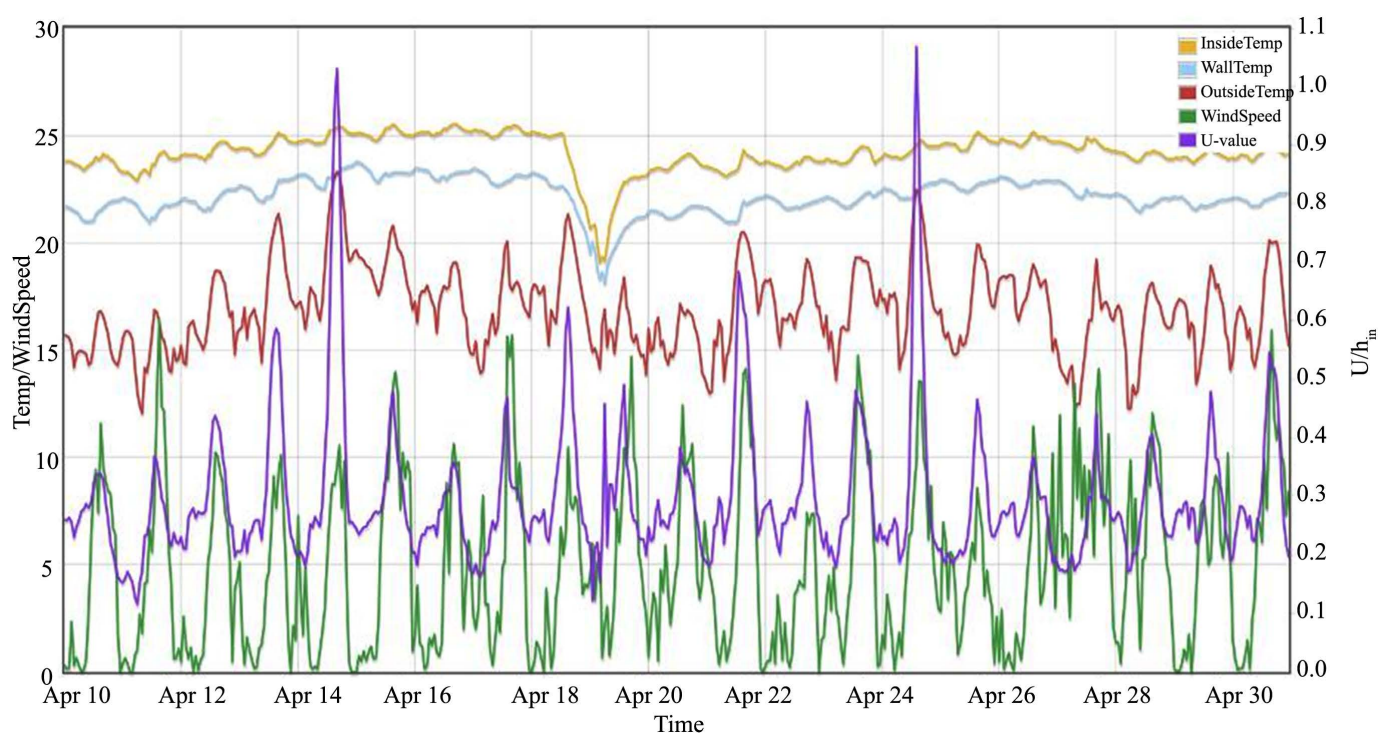

Figure 5. U value metering campaign; the case of a wall.

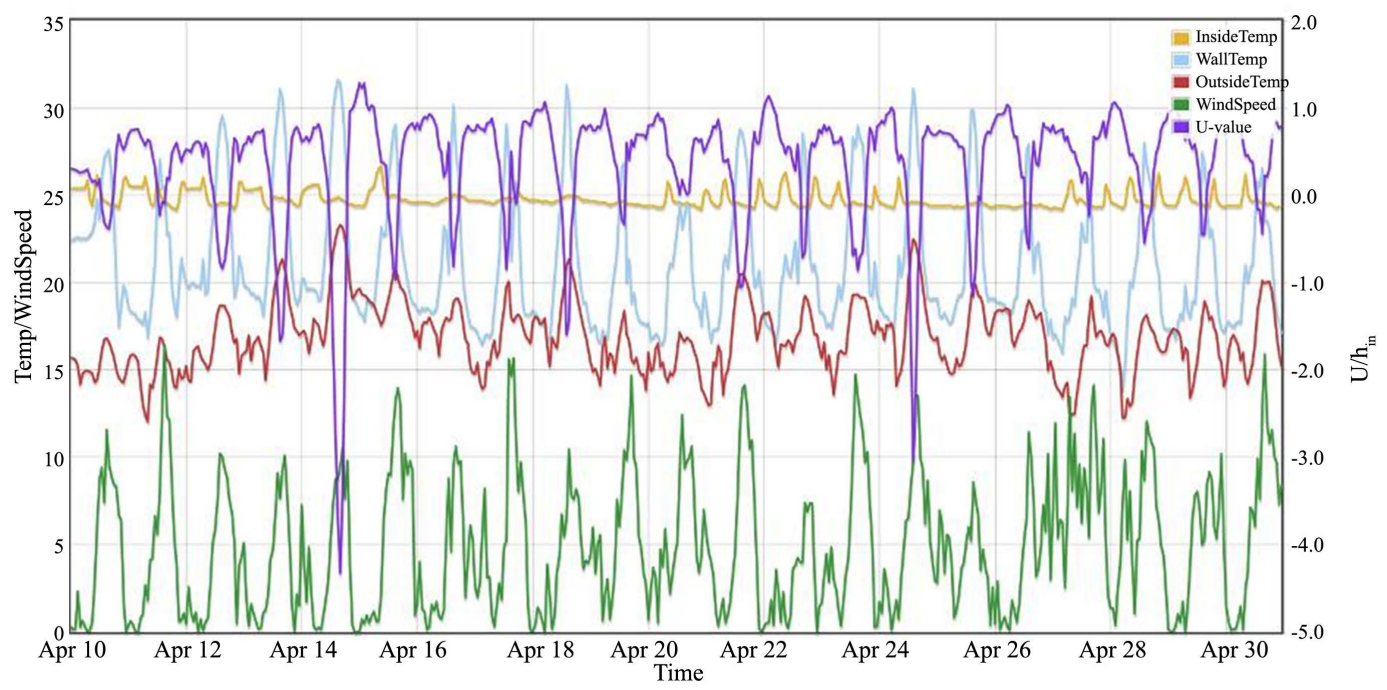

Figure 6. U value metering campaign; the case of a window; note the negative pseudo U values because of sunlight exposure and glazing overheating.

calculated. This is due to window overheating. Obviously, they should not be taken into any account during the calculation. Even more, by adopting a night monitoring campaign such values will not appear.

The wall element shown in the Figure 3, was estimated analytically by two different providers as having a U value ranging between 1.13 and $0.45 \mathrm{~W} / \mathrm{m}^{2} \mathrm{~K}$. This only illustrates the great uncertainty that characterizes $\mathrm{U}$ value investigations. In our case and for an internal surface resistance $h_{\text {in }}$ that we have estimated among 5 and 6 $\mathrm{W} / \mathrm{m}^{2} \mathrm{~K}$, our dynamic and real time estimation of the $\mathrm{U}$ value ranges between 1 and $1.5 \mathrm{~W} / \mathrm{m}^{2} \mathrm{~K}$. An average value needs to be assessed here, which would require some further work discussed in the next section.

\section{Conclusions}

A compact and non-intrusive technology for $\mathrm{U}$ value metering has been presented. The technology is based on the real time scanning of three temperatures, the indoor the outdoor and the wall temperature. In the case of a retrofit, where our interest lies in the change of the $U$ value, the metered wall must be the one that is not retrofitted; in this way the same value of surface resistance can be assumed, before and after the retrofit. It is also important 
to note that the dependence of the $U$ value on wind velocity may now be assessed.

The emphasis has been on developing a practical and non-intrusive solution, at the expense perhaps of some accuracy because of our approximation of the surface resistance $\left(h_{\text {in }}\right.$ or $\left.h_{\text {out }}\right)$. However, in the case of retrofits and in estimating the $U$ value change there is no reason to anticipate any loss of accuracy as the method is not affected by any surface resistance considerations.

At the moment of this writing data collection is on-going. In the next months the retrofits will be carried out and the campaign will continue after the retrofit, so that the retrofit impact can be evaluated according to what has been presented above.

\section{Discussion-Further Research}

Although data have been collected some important data filtering and processing will be necessary before any $\mathrm{U}$ value approximations may be reported. This is mandated by the following:

1) Only nighttime data should be considered to avoid the complex interaction of the sun with the building elements resulting to overheating and pseudo $U$ values.

2) It may be appropriate to, more generally, restrict to steady state periods, where the wall temperature is not changing. We will need to evaluate whether this practice will result to any difference as to when all data (in steady state and transient periods alike) are used.

3) An important investigation is the averaging period that is required to reach some safe estimate. We would expect this to be something like a few days, maybe even less, however the differences between various time periods need to be checked and evaluated. Obviously, the sooner the averaging converges the better for the applicability of the technology.

Besides the above data processing issues, the $U$ value change assessment is also a key point in our investigation that will be performed towards the middle of next year, when the retrofits will be over and data collection will then automatically extend over to the post retrofit period and the assessment of the new $U$ values.

In a next paper, at that time, we will report on the details of these issues.

\section{Acknowledgements}

The work presented in this paper is partly funded by the European Commission within the 7th Framework Programme (RESSEEPE Project, Grant agreement no: 609377).

\section{References}

[1] IEA (International Energy Agency) (2008) Worldwide Trends in Energy Used and Efficiency—Key Insights from IEA Indicator Analysis. IEA Publications, Paris.

[2] Doran, S. (2003) Improving the Thermal Performance of Buildings in Practice. BRE Project Report 16476. Subsequently Published as BRE Client Report 222392-2005. Watford, BRE.

[3] Doran, S. (2008) Thermal Transmittance of Walls of Dwellings before and after Application of Cavity Wall Insulation. Prepared for: James Russill, Energy Saving Trust. BRE Report Number 222077.

[4] Baker, P. (2011) Technical Paper 10-U-Values and Traditional Buildings. Historic Scotland, Edinburgh.

[5] Rye, C. and Scott, C. (2010) The SPAB Research Report 1: The U-Value Report. Revised 2011. The Society for the Protection of Ancient Buildings, London.

[6] Ward, T. (1993) In Situ Measurements of the U-Value of Walls of Several Different Constructions. Building Research Establishment Note. No 66/93.

[7] Hulme, J. and Doran, S. (2014) In-Situ Measurements of Wall U-Values in English Housing. Prepared for: Alex Boss, DECC. BRE Output Number 290-102.

[8] Ortega, R., Loria, A. and Kelly, R. (1995) BS EN ISO 6946 Building Components and Building Elements-Thermal Resistance and Thermal Transmittance-Calculation Method.

[9] Xeni, F., Eleftheriou, P., Michaelides, I., Hadjiyiannis, S., Philimis, P. and Stylianou, A. (2014) In Situ U-Value Measurements for Today’s Cypriot Houses. International Journal of Sustainable Energy. 